\title{
GRA-AHP BASED APPROACH FOR SELECTION OF GREEN LOGISTICS SUPPLIER: A CASE STUDY OF AN INDIAN PAPER INDUSTRY
}

\author{
A. JAYANT \& T. WALKE \\ Sant Longowal Institute of Engineering and Technology
}

\begin{abstract}
Green Supplier selection is becoming an important issue in supply chain management. In recent years, determining the obtaining green supplier in the supply chain has become a key management consideration. However, these decisions usually involve several factors or criteria, and it is often necessary to eliminate among possibly conflicting factors. Thus, the multiple criteria decision making (MCDM) becomes a very useful and important approach to solve this kind of problem. Considering both tangible and intangible criteria, this study proposes integrated Grey Relational Analysis and Analytical Hierarchy Process (AHP) approach to solve the Green Logistics Supplier Selection problem. The advantage of this method is that it allows decision makers to set multiple aspiration levels for supplier selection problems. The model proposed is illustrated by an example in a paper industry. This is a first of its kind study based on a medium size Indian paper industry.

KEYWORDS: GRA-AHP, MCDM, Logistics
\end{abstract}

Received: Jun 08, 2020; Accepted: Jun 28, 2020; Published: Aug 29, 2020; Paper Id.: IJMPERDJUN2020948

\section{INTRODUCTION}

As businesses move towards increased global competitiveness, the tactical issues surrounding supply management progressively demands the attention of firms forcost reduction, improved quality, better customer service and continuousness of supply which significantly elevates supply chain management stature within organizations (Spekman, 1981; Freeman \&Cavinato, 1990; Cavinato 1991; Monezka, 1992; Watts et al., 1992; Heberling, 1993; Gadde \& Hakansson, 1994; Carter \& Narasimhan, 1996 and Ferguson et al., 1996). Customer pressure encourages companies to implement green practices in their processes and respond with in-kind performance enhancement. An investment in cleaner technologies not only improves the environmental performance but also creates competitive edge and enhances economic performance.

Many companies are investing to adopt green practices including P\&G (Procter \& Gamble), Unilever, and Engro Corporation. Recently, General Motors also invests $\$ 2.5$ billion for adopting green practices in their business. Nowadays, Indian government is also very serious about the environment. According to a report by the organization for economic Co-operation and development, air pollution could cause 6-9 million premature deaths by 2060 , with the biggest mortality rate spike forecasted in India. It is also very likely to cost $1 \%$ of the global GDP, around $\$ 2.6$ trillion annually, in terms of sick days, medical costs and condensed agricultural output, the report added. Organizations are also taking part in making the production processes and logistics as green as possible. As a result, Green Supply Chain Management (GSCM) turns out to be a new systematic environmental approach in supply chain management and has been repeatedly accepted and practices by forward-thinking organization. 
This paper is organized as follows. In section 2, the GRA-AHP approach is discussed. Subsequently, in section 3, paper industry case study is discussed. In the section 4, proposed decision support system steps are explained. The section5 evaluates green logistics suppliers. In the section 6, managerial implications of the model discussed. Finally, section 7 discusses conclusion \& future research directions.

\section{GRA-AHP-TOPSIS METHOD}

Analytic Hierarchy Process (AHP), since its development, has been a tool used by the hands of decision makers and academics; and it has become one of the most widely used multiple criteria decision-making technique. Many highly recognized works have been published based on AHP: they include usage of AHP in different fields such as planning, selecting the best alternative, resource allocation, resolving conflict, optimization, and numerical extensions of AHP. Bibliographic review of the multiple criteria decision-making tools undertaken by Steuer [118] is alsoimportant.AHP is a multiple criterion decision-making tool that uses eigen value approach to the pair - wise comparisons. It also provides a methodology to calibrate the numeric scale for the calculation of quantitative as well qualitative performances of the attributes. The scale ranges from 1/9 for "least important than", to 1 for "equal", and to 9 for "absolutely more valued than" covering the entire spectrum of the comparison.

The Grey System Theory was proposed by Deng in the year 1982 has been proven to be useful for dealing with poor, partially complete, and uncertain information. The grey relational analysis that is based on the grey system theory by Deng can be used to solve the complex interrelationships among more than one performance characteristics effectively. Through the grey relational analysis, a grey relational grade is calculated to evaluate the multiple performance characteristics. As a result, optimization of the these complex performance factors can be converted into optimization by a single grey relational grade.

In the grey relational analysis, the experimental results are first normalized to the range between zero and one, which is also called the grey relational generating. Next, the grey relational coefficient is derived from the normalized experimental results to express the association between the desired and actual experimental results. Then, the grey relational grade is computed by averaging the grey relational coefficient agreeing to each performance characteristic. The overall evaluation of the multiple performance characteristics is based on the grey relational grade. As a result, optimization of the complex multiple performance characteristics can be converted into optimization of a single grey relational grade. Ideal level of the process parameters is the level with the highest grey relational grade.

The mathematics of GRA is calculated from space theory. The purpose of grey relational analysis is to measure the relative impact of the compared series on the reference series. In other words, the calculation of GRA reveals the relationship between two discrete series in a Grey space.

The MCDM approach based on GRA-AHP is explained in the following steps:

\section{AHP}

- Step 1: Generation and normalization of pairwise matrix using the following equation for normalization.

$$
\mathrm{Nij}=\frac{c_{1 j}}{\sum_{i=1} C_{i j}}
$$


- Step 2: Calculation of weights of each criterion by taking average of each row of pairwise matrix. A weight matrix is generated.

- $\quad$ Step 3: Consistency analysis by multiplying pairwise matrix and weight matrix using equation 2.

$$
\left[\begin{array}{ccc}
C_{11} & \cdots & C_{1 n} \\
\vdots & \cdots & \vdots \\
C_{\mathrm{mj}} & \cdots & C_{\mathrm{mm}}
\end{array}\right] *\left[\begin{array}{c}
W_{11} \\
W_{i 1} \\
W_{\mathrm{m}}
\end{array}\right]=\left[\begin{array}{c}
V_{11} \\
V_{11} \\
V_{\mathrm{m} 1}
\end{array}\right]
$$

- Step 4: Then the consistency vector is obtained. To do this, the weighted sum vector is divided by corresponding. The following formula is used to do the same.

$$
C_{V_{i j}}=\frac{1}{W_{i j}}
$$

- Step 5: The consistency is calculated by using the eigenvalue, $\lambda_{\max }$, to calculate the consistency index, CI. Consistency can be checked by taking the consistency ratio (CR) of CI with the appropriate value in Table 2 . The $\mathrm{CR}$ is acceptable if it is lower than 0.10 . Or else the decision matrix is inconsistent.

$$
\begin{aligned}
& \lambda_{\max }=\frac{\sum_{i=1}^{m} C_{i j}}{m} \\
& C I=\frac{A_{\max }-m}{m-1} \\
& C R=\frac{c l}{\text { Random Index }}
\end{aligned}
$$

\section{GRA}

- Step 6: Generation and normalization of decision matrix using following equation:

$$
x_{i j}=\frac{x_{i j}-\left[x_{i j}\right. \text { min }}{\left(x_{i j}\right) \max -\left[x_{i j} \min \right.}
$$

- Step 7: Then the Grey Relational Coefficient is calculated using following equation.

$$
C\left(N_{0 j}, N_{i j}=\frac{\nabla_{\min }+p \nabla_{\max }}{\nabla_{i j}+p \nabla_{\max }}\right.
$$

Where, $\nabla \mathrm{ij}=|\mathrm{N} 0 \mathrm{j}-\mathrm{Nij}| ; \nabla \min =\operatorname{MIN}(\nabla \mathrm{ij}, \mathrm{i}=1,2,3, \ldots \mathrm{m}, \mathrm{j}=1,2,3, \ldots \mathrm{n})$;

$$
\nabla \max =\operatorname{MAX}(\nabla i j, i=1,2,3, \ldots m, j=1,2,3, \ldots n
$$

- Step 8: Grey Relational Grade is calculated using eq. 9. It is actually the multiplication of Grey relation Coefficient Matrix and Weight Vector.

$\mathrm{G}(\mathrm{x} 0, \mathrm{xi})=\sum_{j=1}^{n} W_{j},\{$ For $\mathrm{i}=1,2,3, \ldots \mathrm{m}\}$

$w_{\mathrm{j}}$ is the weight for attributes, $\mathrm{j}=1,2,3, \ldots \mathrm{n}$. and moreover $\Sigma_{j=1} w_{j}=1$

- A set of alternatives can be preference ranked in descending order of Gi. In this, larger index values indicate better performance of the alternatives. 


\section{PROBLEM DESCRIPTION}

An Indian paper industry (company A) is chosen for this study. Company XYZ has approximately 600 employees per shift; they make corrugated boxes for many multinational companies in India. Products such as television sets, refrigerators, fruits, etc. are kept in these boxes by these companies. The company is one of the leaders in its product segment in North Indian region.

This company has proposed changes in the structure of the final product in order to make it greener, free of harmful chemicals, recyclable, and to lower its electricity consumption. These changes also meet the requirements of environmental law and the needs of their customers. The company is also committed to product life cycle (LCA) analysis of the product. The LCA conducts a series of waste disposal, waste disposal, and waste disposal, and this invention allows the company to evaluate its use of such resources and implement mitigation measures.

In India, in accordance with the rules of Solid Wastage Management (SWM), 2016, by the Union Ministry of Environmental, Forests and Climate Change (MoEF \& CC), all companies present in the sector are now required to take responsibility for their post-purchase products. The impact on the product and the environment. Thanks to the mandate of the Indian government, companies recognize that offering greener products not only meets the needs of customers but also requires finding the right green suppliers to improve the management of their package.

Because of this new context in India, the company's owner seeks a way to identify and to select suppliers who will support the company's adoption of GSCM practices. Among all the present suppliers of the company, 4 major suppliers have been identified as candidates for company A.

According to the principles of feasibility, systematic independence, hierarchy, comparability, dynamics, flexibility and completeness, this research designs 13 green supplier evaluation criteria. From the previous studies and green supplier strategy assessment, and by referring to the supplier selection decision criteria in previous studies, discarded redundant criteria and combined similar criteria. During the process of selecting criteria, in addition to the traditional decision criteria for green supplier selection, in the process of understanding the company's actual operating conditions and requirements on its suppliers, we learned that the raw materials or parts provided by previous suppliers did not have good after-sales service, and the company often had to deal with defective products by itself. Because of this, sometimes damage to the environment was inflicted. So, in order to realize the sustainable development of the company, a criterion of after-sales service was added after the discussion of experts.

Therefore, the final list consists of 13 criteria. These are ISO 14001 Certification (C1), Green Logistics (C2), Commitment of Senior Management to GSCM (C3), Green Purchasing (C4), Product Designs that Avoid/Reduce Toxic/Hazardous Material Use (C5), Product Designs that Reduce/Reuse/Recycle/Reclaim Materials, Components, Or Energy (C6), Compliance with Legal Environmental Requirements as Prescribed By Government of India (C7), Green Packing and Labelling (C8), Waste Management and Pollution Prevention Systems (C9), Willingness to Work with Clients to make the Supply Chain Greener (C10), Green Technologies for Manufacturing (C11), Green Warehousing (C12), AfterSales Services (C13).

According to the purpose of the company, we prepared questionnaires to evaluate 4 suppliers, sent the questionnaire to the academic expert group for content analysis and improvement and chose three experienced senior management personnel of the panel (the selected decision makers not only have a deep understanding of the company's 
business strategy and operation strategy, but also are familiar with the company's procurement strategy, supplier selection process and procurement performance results).

The pairwise analysis of all the criteria was done by all three experts. To avoid inconsistency, a final pairwise matrix was generated by taking the average of the pairwise matrix of the three experts.

\section{DECISION SUPPORT SYSTEM FOR SELECTION OF GREEN LOGISTICS SUPPLIERS}

The proposed decision support system required for the assessment of Selection of Green Logistics Suppliers in two steps: (i) Initial screening of the providers by a team of concerned managers from industry and (ii) GRA-AHP based decision support system for the final evaluation of the suppliers. Often, the initial screening of the suppliers is an easy task but the final selection from the list of short-listed suppliers is a difficult task. In this section, we present a methodology for the initial screening of the providers. Later, these selected providers would be ranked by the GRA-AHP based approach.

The steps of decision support methodology are enlisted as follows:

- Formation of a team of senior managers \& consultants.

- Identification of potential green logistics suppliers in the business environment.

- Identification of criterions based on literature review.

- Preparation of decision matrix and pairwise matrix with the assistance of industry experts and researchers.

- Final selection using GRA- AHP approach and agreement of services offered by the service providers.

GRA-AHP based decision modeling methodology, which is discussed in the next section of the paper, is recommended for the final selection of a green supplier.

\section{EVALUATION OF GREEN LOGISTICS SUPPLIER SELECTION USING GRA-AHP APPROACH}

Implementation of GRA-AHP-TOPSIS model and analysis are explained in the following 8 steps:

- Step 1: Generation and normalization of pairwise matrix using the equation 1 for normalization. The Table 1 shows the pairwise matrix generated along with the column sum at the bottom. Table 2 shows the Normalized matrix generated for the pairwise matrix.

- Step 2: Calculation of weights of each criterion by taking average of each row of pair wise matrix. A weight matrix is generated. Table 3 shows the calculated weights of the respective criterions. Figure 1 demonstrates pictorially.

- Step 3: Consistency analysis by multiplying pair wise matrix and weight matrix using equation 2. Weight sum vector generated is shown in Table 4.

- Step 4: Then the consistency vector is obtained using equation 3. The consistency vector table generated is shown in Table 5.

- Step 5: The consistency is determined by using the eigenvalue, $\lambda_{\max }$, using equations 4,5 and 6 .

$\lambda_{\max }=\frac{(14,78+12+9+14.95+4.84+14.92+14.64+15.23+15+15.2+14.631 .64+14.47907+15.30202+15.4459)}{12}=14.848$ 


$$
\begin{aligned}
& C I=\left(\frac{14848-18}{12-1}\right)=0.154 \\
& C R=\frac{0.154}{1.56}=\mathbf{0 . 0 9 8 7},
\end{aligned}
$$

Which is less than 0.1 , hence the results are consistent. The value 1.56 is given by taken for 13 criterions.

Table 1: Pairwise Matrix

\begin{tabular}{|c|c|c|c|c|c|c|c|c|c|c|c|c|c|}
\hline CRITERIA & C1 & C2 & C3 & C4 & C5 & C6 & C7 & C8 & C9 & C10 & C11 & C12 & C13 \\
\hline C1 & 1.00 & 0.20 & 0.33 & 1.00 & 0.33 & 1.00 & 0.20 & 0.14 & 0.20 & 0.20 & 0.33 & 0.33 & 0.33 \\
\hline C2 & 5.00 & 1.00 & 0.33 & 1.00 & 0.20 & 1.00 & 0.20 & 0.20 & 0.20 & 0.33 & 0.20 & 0.14 & 0.33 \\
\hline C 3 & 3.00 & 3.00 & 1.00 & 5.00 & 3.00 & 3.00 & 1.00 & 1.00 & 1.00 & 1.00 & 3.00 & 0.20 & 3.00 \\
\hline C4 & 1.00 & 1.00 & 0.20 & 1.00 & 0.20 & 0.33 & 0.14 & 0.14 & 0.33 & 0.20 & 0.33 & 0.14 & 0.33 \\
\hline C5 & 3.00 & 5.00 & 0.33 & 5.00 & 1.00 & 3.00 & 0.33 & 0.33 & 0.33 & 1.00 & 3.00 & 1.00 & 0.20 \\
\hline C6 & 1.00 & 1.00 & 0.33 & 3.00 & 0.33 & 1.00 & 0.20 & 0.14 & 0.33 & 0.20 & 0.33 & 0.20 & 1.00 \\
\hline C7 & 5.00 & 5.00 & 1.00 & 7.00 & 3.00 & 5.00 & 1.00 & 1.00 & 3.00 & 1.00 & 5.00 & 3.00 & 5.00 \\
\hline C8 & 7.00 & 5.00 & 1.00 & 7.00 & 3.00 & 7.00 & 1.00 & 1.00 & 3.00 & 3.00 & 5.00 & 3.00 & 1.00 \\
\hline C9 & 5.00 & 5.00 & 1.00 & 3.00 & 3.00 & 3.00 & 0.33 & 0.33 & 1.00 & 3.00 & 3.00 & 1.00 & 1.00 \\
\hline C10 & 5.00 & 3.00 & 1.00 & 5.00 & 1.00 & 5.00 & 1.00 & 0.33 & 0.33 & 1.00 & 3.00 & 1.00 & 1.00 \\
\hline C11 & 3.00 & 5.00 & 0.33 & 3.00 & 0.33 & 3.00 & 0.20 & 0.20 & 0.33 & 0.33 & 1.00 & 0.20 & 0.33 \\
\hline C12 & 3.00 & 7.00 & 5.00 & 7.00 & 1.00 & 5.00 & 0.33 & 0.33 & 1.00 & 1.00 & 5.00 & 1.00 & 1.00 \\
\hline C13 & 3.00 & 3.00 & 0.33 & 3.00 & 5.00 & 1.00 & 0.20 & 1.00 & 1.00 & 1.00 & 3.00 & 1.00 & 1.00 \\
\hline $\begin{array}{l}\text { COLUMN } \\
\text { SUM }\end{array}$ & $\mathbf{4 5 . 0 0}$ & $\mathbf{4 4 . 2 0}$ & $\mathbf{1 2 . 2 0}$ & $\mathbf{5 1 . 0 1}$ & $\mathbf{2 1 . 4 0}$ & $\mathbf{3 8 . 3 4}$ & $\mathbf{6 . 1 4}$ & $\mathbf{6 . 1 6}$ & $\mathbf{1 2 . 0 7}$ & $\mathbf{1 3 . 2 7}$ & $\mathbf{3 2 . 2 0}$ & $\mathbf{1 2 . 2 2}$ & $\mathbf{1 5 . 5 3}$ \\
\hline
\end{tabular}

Table 2: Normalized Matrix

\begin{tabular}{|c|c|c|c|c|c|c|c|c|c|c|c|c|c|}
\hline CRITERIA & C1 & C2 & C3 & C4 & C5 & C6 & C7 & C8 & C9 & C10 & C11 & C12 & C13 \\
\hline C1 & 0.0222 & 0.0045 & 0.0273 & 0.0196 & 0.0156 & 0.0261 & 0.0326 & 0.0232 & 0.0166 & 0.0151 & 0.0103 & 0.0273 & 0.0215 \\
\hline C2 & 0.1111 & 0.0226 & 0.0273 & 0.0196 & 0.0093 & 0.0261 & 0.0326 & 0.0325 & 0.0166 & 0.0251 & 0.0062 & 0.0117 & 0.0215 \\
\hline C3 & 0.0667 & 0.0679 & 0.0820 & 0.0980 & 0.1402 & 0.0783 & 0.1628 & 0.1623 & 0.0829 & 0.0754 & 0.0932 & 0.0164 & 0.1931 \\
\hline C4 & 0.0222 & 0.0226 & 0.0164 & 0.0196 & 0.0093 & 0.0087 & 0.0233 & 0.0232 & 0.0276 & 0.0151 & 0.0103 & 0.0117 & 0.0215 \\
\hline C5 & 0.0667 & 0.1131 & 0.0273 & 0.0980 & 0.0467 & 0.0783 & 0.0542 & 0.0540 & 0.0276 & 0.0754 & 0.0932 & 0.0818 & 0.0129 \\
\hline C6 & 0.0222 & 0.0226 & 0.0273 & 0.0588 & 0.0156 & 0.0261 & 0.0326 & 0.0232 & 0.0276 & 0.0151 & 0.0103 & 0.0164 & 0.0644 \\
\hline C7 & 0.1111 & 0.1131 & 0.0820 & 0.1373 & 0.1402 & 0.1304 & 0.1628 & 0.1623 & 0.2487 & 0.0754 & 0.1553 & 0.2455 & 0.3219 \\
\hline C8 & 0.1556 & 0.1131 & 0.0820 & 0.1373 & 0.1402 & 0.1827 & 0.1628 & 0.1623 & 0.2487 & 0.2261 & 0.1553 & 0.2455 & 0.0644 \\
\hline C9 & 0.1111 & 0.1131 & 0.0820 & 0.0588 & 0.1402 & 0.0783 & 0.0542 & 0.0540 & 0.0829 & 0.2261 & 0.0932 & 0.0818 & 0.0644 \\
\hline C10 & 0.1111 & 0.0679 & 0.0820 & 0.0980 & 0.0467 & 0.1304 & 0.1628 & 0.0541 & 0.0276 & 0.0754 & 0.0932 & 0.0818 & 0.0644 \\
\hline C11 & 0.0667 & 0.1131 & 0.0273 & 0.0588 & 0.0156 & 0.0783 & 0.0326 & 0.0325 & 0.0276 & 0.0251 & 0.0311 & 0.0164 & 0.0215 \\
\hline C12 & 0.0667 & 0.1584 & 0.4099 & 0.1373 & 0.0467 & 0.1304 & 0.0542 & 0.0540 & 0.0829 & 0.0754 & 0.1553 & 0.0818 & 0.0644 \\
\hline C13 & 0.0667 & 0.0679 & 0.0273 & 0.0588 & 0.2337 & 0.0261 & 0.0326 & 0.1623 & 0.0829 & 0.0754 & 0.0932 & 0.0818 & 0.0644 \\
\hline
\end{tabular}

Table 3: Weights of Criteria

\begin{tabular}{|l|l|l|l|l|l|l|l|l|l|l|l|l|l|} 
Criteria & C1 & C2 & C3 & C4 & C5 & C6 & C7 & C8 & C9 & C10 & C11 & C12 & C13 \\
\hline
\end{tabular}

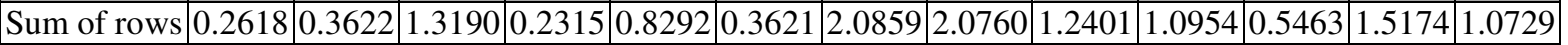
\begin{tabular}{|l|l|l|l|l|l|l|l|l|l|l|l|l|l|l|l|}
\hline Weight & 0.0201 & 0.0279 & 0.1015 & 0.0178 & 0.0638 & 0.0279 & 0.1605 & 0.1597 & 0.0954 & 0.0843 & 0.0420 & 0.1167 & 0.0825 \\
\hline
\end{tabular}

Table 4: Weighted Sum Vector

\begin{tabular}{|l|c|c|c|c|c|c|c|c|c|c|c|c|c|}
\hline CRITERIA & C1 & C2 & C3 & C4 & C5 & C6 & C7 & C8 & C9 & C10 & C11 & C12 & C13 \\
\hline
\end{tabular} \begin{tabular}{|l|c|c|c|c|c|c|c|c|c|c|c|c|c|}
\hline WSV & 0.2976 & 0.3846 & 1.5063 & 0.2607 & 0.9518 & 0.4077 & 2.4604 & 2.3949 & 1.4499 & 1.2329 & 0.6085 & 1.7863 & 1.2748 \\
\hline
\end{tabular} 


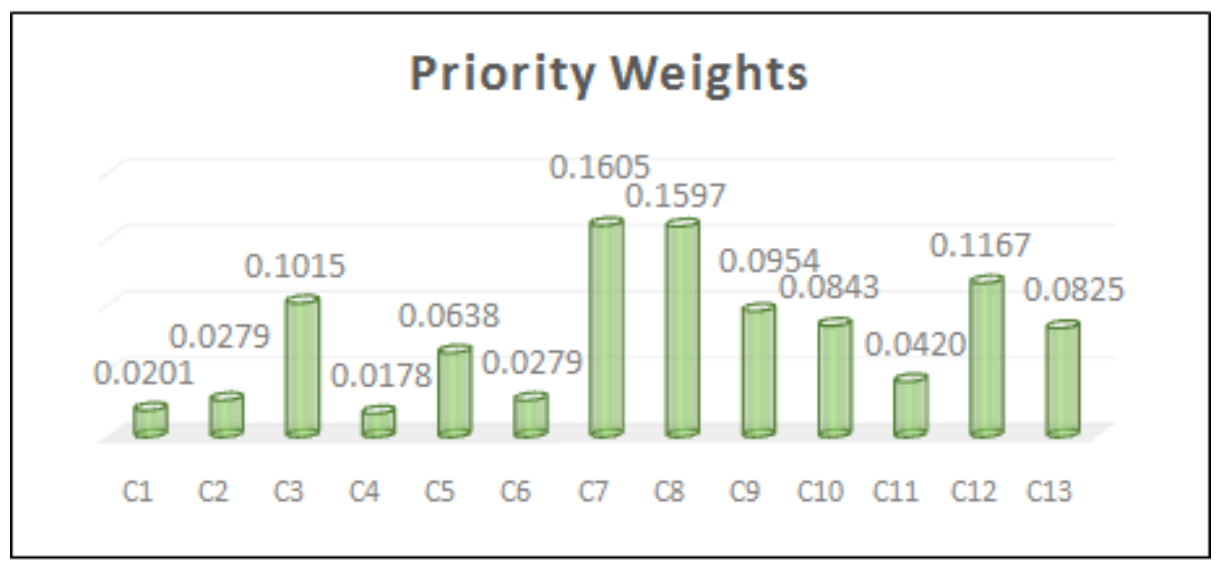

Figure 1: Priorities and Weights of Criterions.

Table 5: Consistency Vector

\begin{tabular}{|c|c|c|c|c|c|c|c|c|c|c|c|c|c|}
\hline Criteria & C1 & C2 & C3 & C4 & C5 & C6 & C7 & C8 & C9 & C10 & C11 & C12 & C13 \\
\hline
\end{tabular}

\begin{tabular}{l|l|l|l|l|l|l|l|l|l|l|l|l|l|}
$\mathrm{CV}$ & 14.7811 & 13.8040 & 14.8452 & 14.6383 & 14.9226 & 14.6368 & 15.3335 & 14.9973 & 15.1992 & 14.6316 & 14.4791 & 15.3030 & 15.4459 \\
\hline
\end{tabular}

- $\quad$ Step 6: Generation and normalization of decision matrix using equation 7, which is shown in Table 6.

Table 6: Decision Matrix

\begin{tabular}{|l|c|c|c|c|c|c|c|c|c|c|c|c|c|}
\hline \multicolumn{10}{|c|}{ Atributes/Criterions } \\
\hline Alternative & C1 & C2 & C3 & C4 & C5 & C6 & C7 & C8 & C9 & C10 & C11 & C12 & C13 \\
\hline GLS1 & 9.00 & 7.00 & 8.00 & 8.00 & 7.00 & 6.00 & 7.00 & 6.00 & 8.00 & 8.00 & 8.00 & 9.00 & 8.00 \\
\hline GLS2 & 7.00 & 8.00 & 6.00 & 8.00 & 6.00 & 8.00 & 9.00 & 8.00 & 6.00 & 7.00 & 9.00 & 9.00 & 9.00 \\
\hline GLS3 & 5.00 & 6.00 & 7.00 & 9.00 & 8.00 & 6.00 & 8.00 & 9.00 & 7.00 & 9.00 & 9.00 & 9.00 & 7.00 \\
\hline GLS4 & 8.00 & 5.00 & 8.00 & 8.00 & 9.00 & 5.00 & 8.00 & 9.00 & 5.00 & 7.00 & 8.00 & 7.00 & 6.00 \\
\hline GLS5 & 7.00 & 6.00 & 7.00 & 5.00 & 6.00 & 7.00 & 6.00 & 7.00 & 5.00 & 3.00 & 7.00 & 9.00 & 7.00 \\
\hline MAX-MIN & 4.00 & 3.00 & 2.00 & 4.00 & 3.00 & 3.00 & 3.00 & 3.00 & 3.00 & 6.00 & 2.00 & 2.00 & 3.00 \\
\hline MIN & 5.00 & 5.00 & 6.00 & 5.00 & 6.00 & 5.00 & 6.00 & 6.00 & 5.00 & 3.00 & 7.00 & 7.00 & 6.00 \\
\hline
\end{tabular}

- Step 7: Then the Grey Relational Coefficient is calculated using equation 8, as shown in Table 7.

Table 7: Grey Relation Generation

\begin{tabular}{|l|c|c|c|c|c|c|c|c|c|c|c|c|c|}
\hline \multicolumn{10}{|c|}{ Atributes/Criterions } \\
\hline Alternatives & C1 & C2 & C3 & C4 & C5 & C6 & C7 & C8 & C9 & C10 & C11 & C12 & C13 \\
\hline GLS1 & 0.80 & 0.50 & 0.33 & 0.75 & 0.25 & 0.33 & 0.25 & 0.00 & 0.60 & 2.50 & 0.17 & 0.29 & 0.40 \\
\hline GLS2 & 0.67 & 0.60 & 0.00 & 0.75 & 0.00 & 0.60 & 0.50 & 0.40 & 0.33 & 4.00 & 0.29 & 0.29 & 0.50 \\
\hline GLS3 & 0.00 & 0.33 & 0.20 & 0.80 & 0.40 & 0.33 & 0.40 & 0.50 & 0.50 & 2.00 & 0.29 & 0.29 & 0.25 \\
\hline GLS4 & 0.75 & 0.00 & 0.33 & 0.75 & 0.50 & 0.00 & 0.40 & 0.50 & 0.00 & 4.00 & 0.17 & 0.00 & 0.00 \\
\hline GLS5 & 0.67 & 0.33 & 0.20 & 0.00 & 0.00 & 0.50 & 0.00 & 0.25 & 0.00 & 0.00 & 0.00 & 0.29 & 0.25 \\
\hline Reference & 1.00 & 1.00 & 1.00 & 1.00 & 1.00 & 1.00 & 1.00 & 1.00 & 1.00 & 1.00 & 1.00 & 1.00 & 1.00 \\
\hline$\nabla_{\min }$ & 0.00 & 0.00 & 0.00 & 0.00 & 0.00 & 0.00 & 0.00 & 0.00 & 0.00 & 0.00 & 0.00 & 0.00 & 0.00 \\
\hline$\nabla_{\max }$ & 0.80 & 0.60 & 0.33 & 0.80 & 0.50 & 0.60 & 0.50 & 0.50 & 0.60 & 4.00 & 0.29 & 0.29 & 0.50 \\
\hline$\rho$ & 0.50 & 0.50 & 0.50 & 0.50 & 0.50 & 0.50 & 0.50 & 0.50 & 0.50 & 0.50 & 0.50 & 0.50 & 0.50 \\
\hline
\end{tabular}

- Step 8: Finally, Grey Relational Grade is calculated using eq. 9, as shown in Table 8. Figure 2 demonstrates pictorially. 
Table 8: Grey Relational Grades and Priorities

\begin{tabular}{|c|c|c|}
\hline Alternatives & Grey Relational Grade & Priorities \\
\hline GLS1 & 0.8663 & $\mathbf{3}$ \\
\hline GLS2 & 0.8780 & $\mathbf{2}$ \\
\hline GLS3 & 0.9197 & $\mathbf{1}$ \\
\hline GLS4 & 0.8315 & $\mathbf{4}$ \\
\hline GLS5 & 0.7984 & $\mathbf{5}$ \\
\hline
\end{tabular}

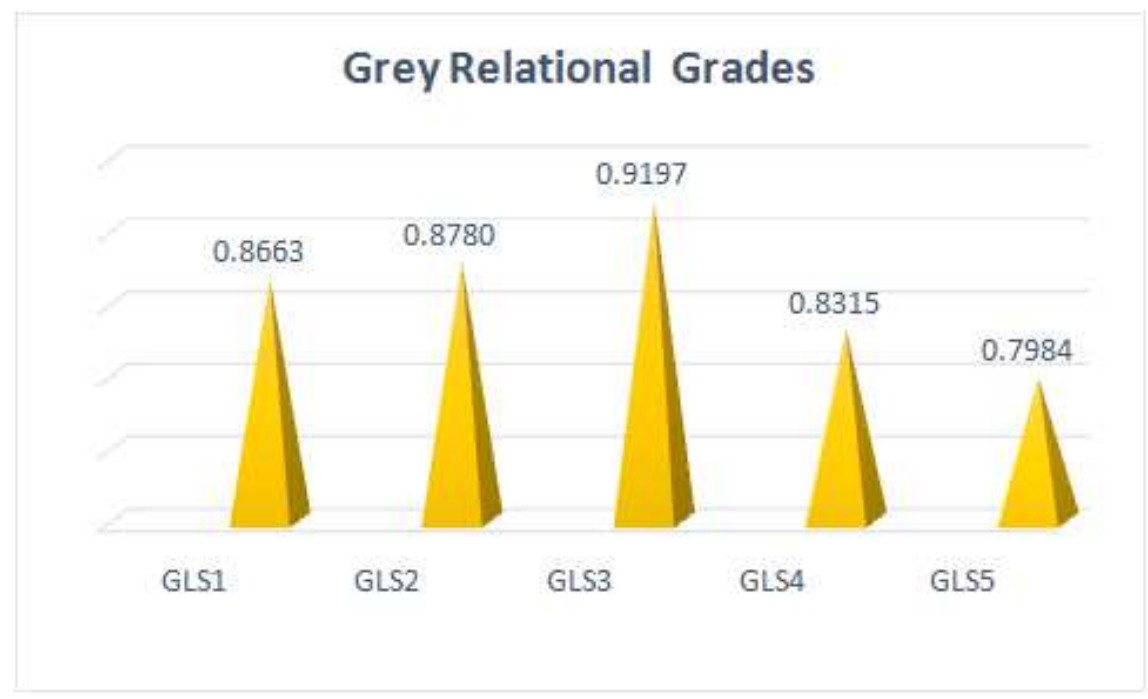

Figure 2: GRA Relational Grades of Alternatives.

Higher the Grade higher will be the priority to the alternative. As shown in Table 8.Here, after the application of GRA, we got the priorities order GLS $3>$ GLS $2>$ GLS $1>$ GLS $4>$ GLS 5.It is clear here that these results must be seen in the light of the business environment of paper industry and the inputs provided by a team of experts in the pair-wise comparison of the attributes.

\section{DISCUSSIONS AND MANAGERIAL IMPLICATIONS}

The proposed hybrid model in the present research has find out several significant attributes for evaluation of green logistics suppliers for a paper industry. It was found that among all the criterions evaluated, the criteria with maximum weight age is C8, i.e. Commitment of Senior Management To GSCM. This was followed by Waste Management and Pollution Prevention (C8), Product designs that reduce, reuse, recycle, or reclaim materials, components, or energy (C12), Compliance with legal environmental requirements and auditing programs (C3), Green Logistics (C9), Product designs that avoid or reduce toxic or hazardous material use (C13), Green Packing and Labelling (C10), ISO 14001 Certification (C5), Green Purchasing (C11), Green Manufacturing Technologies (C6), Willingness to Work with clients for making the supply chain greener (C2), After Sales Services (C1) and Green Warehousing (C4) respectively.C7 and C8 scored very close to each other after the results, This means that both Commitment of Senior Management to GSCM and Waste Management and Pollution Prevention of the suppliers will play a crucial role in selection of the supplier in Paper Industry. Also, Product designs that reduce, reuse, recycle, or reclaim materials, components, or energy (C12) and Compliance with legal environmental requirements and auditing programs (C3), the next two criterions scored comparable values. So, for the Corresponding company and corresponding industry, these two factors also play a crucial in the selection of the suppliers. We have seen that our consistency ratio is 0.0987 which is less than 0.1 but is very close to 0.1 which indicates that the priorities are quite sensitive. 
After that we used Grey Relational Analysis to form a decision matrix for criterions and alternatives (Green Logistics Suppliers) and calculate Grey Relational Grades to find out which Green Logistics Supplier is closest to the ideal requirements. After the application of GRA, we got the priorities order as GLS $3>$ GLS 2 > GLS $1>$ GLS 4 > GLS5.

This study may provide support to management and consultants for making strategic decisions in selection of green suppliers for the paper industry in an Indian context. The developed model provide flexibility in accommodating new attributes according to industry needs time to time for sound decision making.

Table 9: Criteria List and Resulting Weights

\begin{tabular}{|c|l|c|c|c|}
\hline Code & \multicolumn{1}{|c|}{ Criteria } & Weight & $\begin{array}{c}\text { Percentage } \\
\text { Share }\end{array}$ & Rank \\
\hline C1 & After Sales Services & 0.2976 & 2.01 & 12 \\
\hline C2 & $\begin{array}{l}\text { Willingness to Work with Clients for Making the Supply Chain } \\
\text { Greener }\end{array}$ & 0.3846 & 2.79 & 10 \\
\hline C3 & $\begin{array}{l}\text { Compliance with Legal Environmental Requirements and Auditing } \\
\text { Programs }\end{array}$ & 1.5063 & 10.15 & 4 \\
\hline C4 & Green Warehousing & 0.2607 & 1.78 & 13 \\
\hline C5 & Iso 14001 Certification & 0.9518 & 6.38 & 8 \\
\hline C6 & Green Manufacturing Technologies & 0.4077 & 2.79 & 11 \\
\hline C7 & Commitment of Senior Management To GSCM & 2.4604 & 16.05 & 1 \\
\hline C8 & Waste Management and Pollution Prevention & 2.3949 & 15.97 & 2 \\
\hline C9 & Green Logistics & 1.4499 & 9.54 & 5 \\
\hline C10 & Green Packing and Labelling & 1.2329 & 8.43 & 6 \\
\hline C11 & Green Purchasing & 0.6085 & 4.20 & 9 \\
\hline C12 & $\begin{array}{l}\text { Product Designs That Reduce, Reuse, Recycle, Or Reclaim Materials, }, \\
\text { Components, Or Energy }\end{array}$ & 1.7863 & 11.67 & 3 \\
\hline C13 & $\begin{array}{l}\text { Product Designs That Avoid or Reduce Toxic or Hazardous Material } \\
\text { Use }\end{array}$ & 1.2748 & 8.25 & 7 \\
\hline
\end{tabular}

\section{CONCLUSIONS AND FUTURE SCOPE}

The research provides substantive support to the Indian supply chain management literature and fresh insights about the SC relationship that exists in Indian small-scale industries such as paper industry, bottling industry, etc. There is always a scope for further improvement in the research model, especially in the decision-making models, as no decision is 100 percent accurate, so a comparative study may be conducted by using other multi-criteria decision-making methods to validate the results obtained by present method. ATOPSIS approach may be used by contemplation of the interactions between criterions and the results could be compared by using TOPSIS or GRA MCDM. The criterions were specifically selected for the supplier of an Indian paper industry. If a different industry is selected, some of the criterions may get redundant and may be required to be replaced. Also, the weights of the same criterions may vary as the pairwise matrix will be generated by the industry specific experts. So, a different industry can be researched in the future. Microsoft Excel has been used for calculation purpose in this work. Tailored software may be developed to reduce computational speed and simplification of calculations.

\section{ACKNOWLEDGEMENTS}

The authors extend their gratitude to the management and staff of XYZ Company for providing them with the opportunity to do this work and expand their collaboration on data collection and provide all kinds of support for existing research work. 
The authors also thank the senior and anonymous referees for their constructive comments and important suggestions that led to a major improvement in the paper in this way

\section{REFERENCES}

1. Christoper, M. (1998) Logistics and Supply Chain Management, Strategies for Reducing Cost and Improving Services, 2nd Ed, London.

2. Stadtler, H. (2004) Supply Chain Management and Advanced Planning - Basics, Overview and Challenges, European Journal of Operational Research

3. Spekman, Robert E. "A strategic approach to procurement planning." Journal of Purchasing and Materials Management 17.4 (1981): 2-8.

4. Rao, A. Lakshmana. "An industry analysis with special reference to indian paper industry." International journal of business management \& research (2012): 82-83.

5. Freeman, Virginia T., and Joseph L. Cavinato. "Fitting purchasing to the strategic firm: frameworks, processes, and values." Journal of purchasing and materials management 26.1 (1990): 6-10.

6. Gleim MR (2013) Against the green: a Multimethod examination of the barriers to green consumption. Journal of Retailing:44-61

7. Pal, Shrabanti. "Evaluation of Financial Performance in Terms of Financial Ratios-An Empirical Study on Indian Automobile Industry." International Journal of Business Management \& Research 5.3 (2015): 1-7.

8. Zhu, Qinghua, Joseph Sarkis, and Kee-hung Lai. "Green supply chain management implications for "closing the loop"." Transportation Research Part E: Logistics and Transportation Review 44.1 (2008): 1-18.

9. Saaty, Thomas L. "What is the analytic hierarchy process?" Mathematical models for decision support. Springer, Berlin, Heidelberg, 1988. 109-121.

10. Saaty, Thomas L. "What is the analytic hierarchy process?" Mathematical models for decision support. Springer, Berlin, Heidelberg, 1988. 109-121.

11. Lakshman, R., and A. Ramesh."A System Dynamic Analysis of Energy Consumption and CO2 Emission of Indian Iron and Steel Industries." International Journal of Mechanical Engineering 3.4 (2014): 49-60.

12. Saaty, Thomas L. "How to make a decision: the analytic hierarchy process." European journal of operational research 48.1 (1990): 9-26.

13. Zhang, S.F. and Liu, S.Y. (2011) 'A GRA-based intuitionistic fuzzy multi-criteria Collaboarative Decision method for personnel selection', Expert Systems with Applications, vol.38, p.p.11401-11405

14. Sharma, Savita, and Pradeep K. Goyal. "Cost overrun factors and project cost risk assessment in construction industry-a state of the art review." International Journal of Civil Engineering (IJCE) Vol 3 (2014): 139-154.

15. Zheng, G., Jing, Y., Huang, H., and Gao, Y. (2010) 'Application of improved grey relational projection method to evaluate sustainable building envelope performance', Applied Energy, vol.87, p.p.710-720 